\title{
Biodeterioro del patrimonio artístico por cianobacterias, algas verdes y diatomeas
}

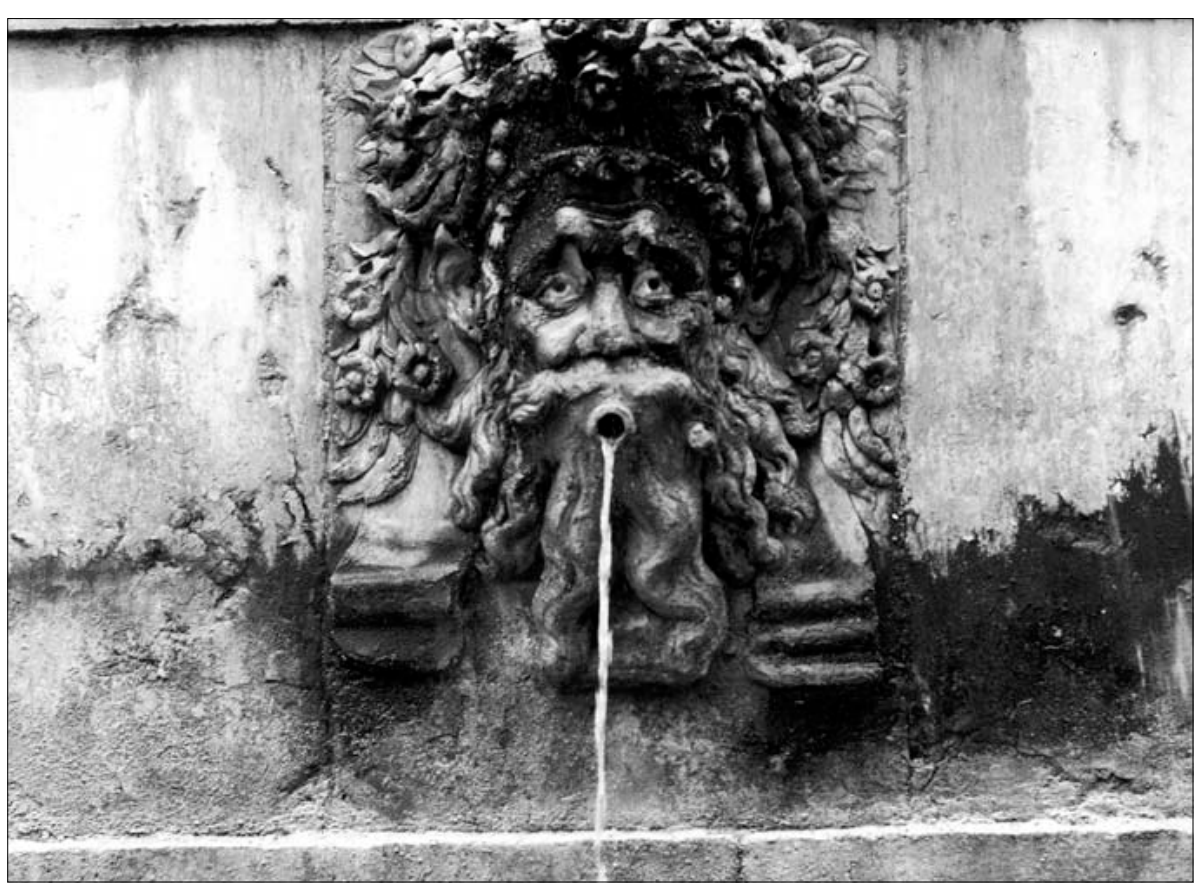

Fernando C. Bolívar Galiano

Departamento de Pintura Facultad de Bellas Artes de Granada Universidad de Granada

Pedro M. Sánchez Castillo Departamento de Biología Vegeral Facultad de Ciencias Universidad de Granada

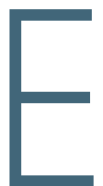

I conocimiento del deterioro monumental por algas (ficodeterioro) podríamos considerar que se produjo durante el estudio de la "polvere rosa", que Giuseppe Meneghini en 1843 inicialmente denomina "colorazione rosata", refiriéndose a una atípica alteración de naturaleza biológica que no consigue identificar con exactitud. En 1917, O. Mattiroli le atribuye un origen bacteriano a este mismo fenómeno observado sobre muros antiguos. Será a partir de 1959 cuando comience el estudio en profundidad a cargo del Laboratorio di Indagini Biologice del Istituto Centrale per il Restauro (ICR), que concluye en 1976 afirmando que se trata de una alteración de origen algal, tras su observación con microscopía electrónica de barrido y la cuantificación de clorofila en cultivo (Giacobini et al, 1987).

Sobre algas que crecen en pintura mural y enlucidos, sólo destacan algunos trabajos de la Universidad de 
Roma (Grilli Caiola y Albertano, 1986; Grilli Caiola et al., 1987; Albertano et al., 199 la y b) y del Instituto Central de Restauración de Roma (Ricci et al., 1985; Pietrini y Ricci, 1993).

Los bienes culturales de naturaleza orgánica, aunque con mucha menor frecuencia, también se ven afectados por microalgas. Por ejemplo, el deterioro de ciertos objetos textiles expuestos a la intemperie se ha relacionado con la presencia de algunas especies de cianobacterias, como Tolypothrix byssoides, así como de mixomicetos, actinomicetos y bacterias no fotosintéticas (Desai y Pandey en Vigo, 1980).

Respecto a los bienes inmuebles podemos destacar el trabajo de Anagnostidis et al. (1983) en el cual se describen las cianobacterias y diatomeas del Partenón de Atenas. Realini et al. (1985) se ocupan de un caso de biodeterioro en el que está implicada una especie de alga verde unicelular (Chlorella sp.). Otros trabajos estudian las cianobacterias o algas azules que afectan a los monumentos de piedra, en combinación con líquenes (Danin y Caneva, 1990) o analizando las sustancias orgánicas endolíticas y su relación con el biodeterioro (Sáiz Jiménez et al., 1990).

En España, se han realizado pocos trabajos sobre diagnosis microalgal en monumentos. Ortega Calvo et al. (1991, I992 y 1993a y b) estudian el biodeterioro por cianobacterias y otras algas en materiales de construcción, utilizando estrategias experimentales de investigación para el caso de la piedra y mediante aislamiento y caracterización en las catedrales de Sevilla, Salamanca y Toledo. Hernández-Mariné et al. (1992) emplean el microscopio electrónico de barrido como instrumento de estudio del biodeterioro en estatuas de terracota de la Catedral de Sevilla, centrándose en las especies allí más abundantes: Microcoleus vaginatus y Klebsormidium flaccidum. Sobre monumentos graníticos podemos citar un estudio de la ficoflora epilítica realizado en el Monasterio de Samos, Lugo (Noguerol y Rifón, 1996).

El estudio de la colonización algal en fuentes monumentales es aún más escaso, sólo podemos citar algunos trabajos parciales de catalogación de diatomeas en la Alhambra y Roma (Foged, 1976 y 1983), de cianofitas y clorofitas en Granada (Sánchez Castillo, 198। y 1983), de análisis biológicos en intervenciones de restauración en Roma (Giacobini y Giuliani, 1987; Pietrini, 1989), sobre la diagnosis y tratamiento del deterioro algal en los palacios de las Alhambra (Bolívar, 1994), sobre la biotipología y resistencia a biocidas de las algas en la Alhambra (Bolívar y Sánchez-Castillo, 1995 y 1996), y sobre la biomineralización por algas en la Alhambra (Bolívar y Sánchez-Castillo, 1997).

\section{TIPOS DE FICODETERIORO EN MONUMENTOS Y OTRAS OBRAS DE ARTE}

En diversos monumentos estudiados se han observado los siguientes mecanismos de deterioro producidos por microalgas:

\section{A) Ficodeterioro de tipo estético}

Las intensas coloraciones y los cambios texturales que producen las algas dan lugar a alteraciones de distita naturaleza y repercusión:

\section{Deterioro funcional (soiling)}

Por absorción del polvo atmosférico, material particulado y residuos carbonosos de la contaminación del aire, las comunidades algales dan lugar a pátinas muy oscuras, principalmente en superficies secas o temporalmente húmedas. Este sería el caso de las pátinas y moteados oscuros en paramentos y esculturas (Fotol). Pero como la mayoría de las algas habitan ambientes eminentemente acuáticos la absorción de partículas disueltas en al agua va a ser el principal mecanismo llevado a cabo por este tipo de organismos. Las algas potencialmente más capacitados para producir este tipo de alteración son las gelatinosas y las filamentosas con vaina.

\section{Interferencia en la lectura de la obra}

Analizando la estética y el simbolismo de ciertos monumentos como los jardines, patios y fuentes monumentales islámicas (Foto 2), se podría pensar que teóricamente el crecimiento de las algas en las fuentes y albercas sería un elemento enriquecedor, ya que están presentes en los manantiales y lagos naturales que son el anhelo de la mentalidad islámica. Esta tendencia naturalista llevó a los artistas musulmanes a recrearse en el empleo del agua, dándole forma vegetal a las fuentes labradas y decorando los muros, techos y capiteles con una decoración polícroma inspirada también en motivos vegetales. De hecho existe cierto paralelismo entre el cromatismo efímero de la "policromía algal" y el rápido proceso de decoloración sufrido por la policromía árabe original de las yeserías y mármoles del arte hispano-musulman, cuyos colores (negro, azul, dorado, rojo y verde) se corresponden con las pátinas algales más características. El problema surge cuando el estado de alteración del sustrato y la contaminación del agua favorecen una proliferación excesiva de estos organismos y posteriormente una rápida deposición de costras carbonatadas, que comienzan provocando efectos cromáticos muy impactantes para el espectador y terminan por sepultar la superficie original bajo numerosas capas calcáreas. 


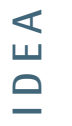

\section{Formación de pátinas}

Observando el elevado rango de variabilidad cromática de las pátinas algales, vemos como se aprecian claras diferencias en la variación estacional. En unas ocasiones existe una gama cromática de pátinas más amplia en primavera y verano que en otoño e invierno y en otras ocasiones el fenómeno es inverso y el espectro es claramente más monótono durante la primavera y el verano.
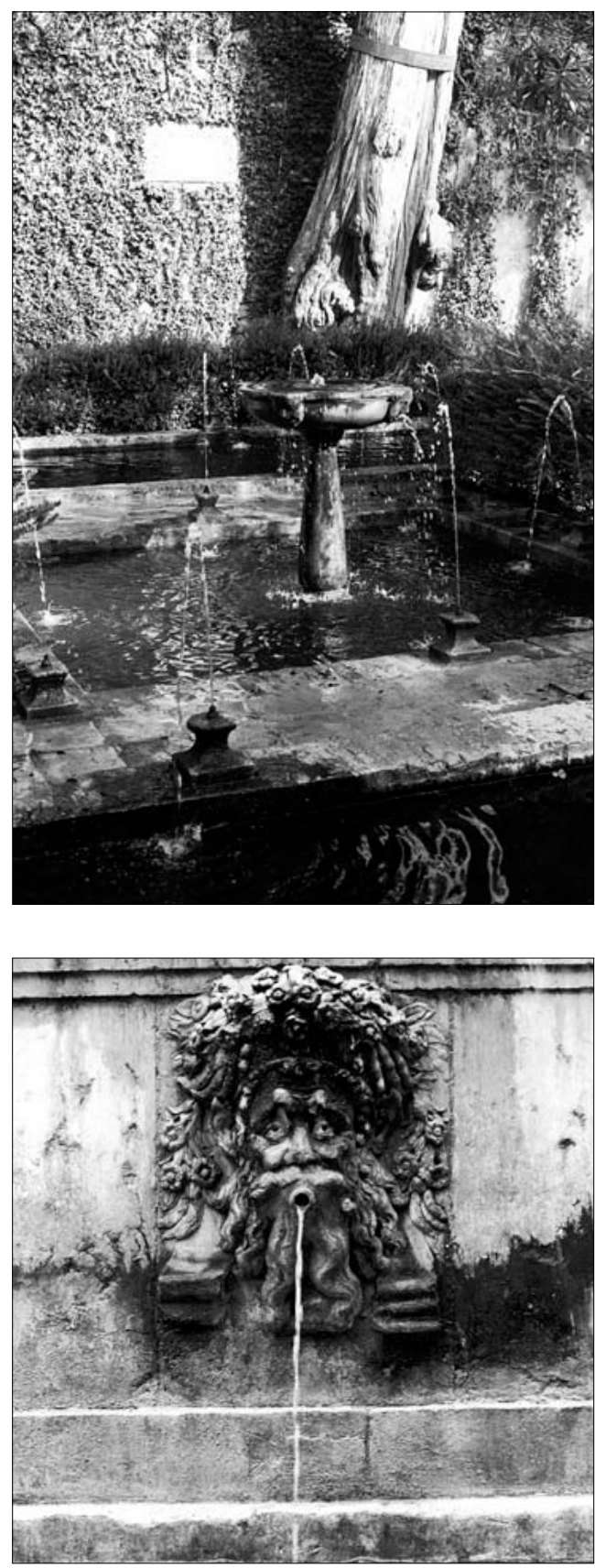

Foto 2: Algas verdes y cianobacterias en el Patio de la Sultana, Generalife (Granada).

Foto 3: Cianobacterias y algas verdes junto y sobre el

Mascarón central del Pilar de Carlos V (Alhambra, Granada).
Respecto a las pátinas más distintivas, como son las rojizas, violáceas y pardonegruzcas, el color rojizo obedece a la presencia de especies o estados vitales muy concretos. Estas pátinas pueden ser debidas a cianobacterias que pueden acumular óxidos de hierro u otras sustancias en sus vainas mucilaginosas (Chamaesiphon polonicus, Pleurocapsa minor, Lyngbya amplivaginata, Calothrix elenkinii y Schizothrix gomonthii) o estar ocasionadas por la presencia de células de resistencia (quistes o acinetos) de algas verdes que sintetizan gran cantidad de carotenoides (Chlorosarcinopsis minor, Tetracystis spp. y Pleurastrum spp., entre otras). Esto explica que en numerosos monumentos aparezcan abundantes pátinas rojizas en las estaciones de mayor dureza climática (invierno y verano), como prueba de los recursos adaptativos de estas especies que se cuentan como las más potencialmente dañinas para el patrimonio (Foto 3).

En el estudio realizado con el fin de obtener una metodología que pueda ser útil en la conservación de obras artísticas afectadas por agentes algales de deterioro (Bolívar Galiano, 1994), se ha podido dar explicación a muchos fenómenos relacionados con el deterioro estético de la Alhambra. Por ejemplo, al observar los espectros cromáticos de las pátinas algales vemos, que aunque las algas azules predominan en la mayoría de ellas, apenas existen comunidades que presenten una clara tonalidad azul. Esto es debido a que el efecto visual macroscópico de las ficocianinas en las cianobacterias queda enmascarado (tornándose verde) con los pigmentos amarillentos de las diatomeas que habitan sobre ellas o por la pigmentación amarilla anaranjada o rojiza.

En esta misma línea, las numerosas y, aparentemente, indescifrables pátinas verdes, nos informan del estado de crecimiento, madurez y complejidad específica de la comunidad, mayor cuanto más oscuro y agrisado sea el verde. Durante el otoño, las pátinas de Fernandinella alpina y Phormidium favosum presentan un tono verde mucho más vivo, en superificies sumergidas que en los surtidores. Los verdes más parduzcos se deben, generalmente, a la presencia de poblaciones de Chamaesiphon polonicus que oscurece la pigmentación verde intensa de Chlorosarcinopsis minor y Scenedesmus spp. Las pátinas ocres están mayoritariamente integradas por diatomeas, por cianobacterias como Pleurocapsa minor y Aphanothece saxicola o por algas verdes como Cylindrocapsa sp.

Muchas de las pátinas algales dan lugar a procesos de migración de sales, mediante producción de sustancias quelantes (polisacáridos con iones alcalinos que se combinan con metales, originando sales), este proceso es conocido con el nombre de "biotransferencia”. Las pátinas algales por sí solas, no son tan permanentes como las de naturaleza química, ya que varían dependiendo de la estacionalidad y se mantienen gracias a la síntesis activa de las células vivas, que van regenerando los pigmentos (Foto 4).

Pátinas más estables son producidas por las algas que se sitúan en el interior de la piedra (endolíticas) pues se mantienen vitales incluso después de intensas tareas de limpieza y restauración, aportando a la piedra una pigmentación verde o rojiza, según el estado fisiológico de las células. Además su actividad origina acúmulos minerales fuertemente adheridos al sustrato que son analizados a continuación.

\section{Formación de concreciones / acreciones}

Según Brachert (1990) se incluirían en el término "pátina", todos los tipos de estratos minerales presentes sobre los objetos arqueológicos que no reaccionan químicamente con el material original (incrustaciones calcáreas sobre piedra y cerámica y las de las piezas arqueológicas submarinas). De esta manera podemos considerar a las algas, como importantes formadoras de pátinas espesas, ya que no sólo determinan la estructura, sino también en muchas ocasiones, el color. Como hemos comprobado en diversos estudios experimentales, las especies algales condicionan la estructura de las deposiciones minerales (Bolívar y Sánchez-Castillo, en prensa).

A partir de micromuestras de concreciones, y tras la realización de sus correspondientes láminas delgadas, se obtuvo la composición elemental cualitativa de formaciones fico-cristalinas en los distintos estratos, mediante el detector EDX para el SEM. Los resultados obtenidos confirman su composición eminentemente calcárea $\left(\mathrm{CO}_{3} \mathrm{Ca}\right)$. Se ha detectado la presencia de silicato alumínico de $\mathrm{Mg}$, $\mathrm{K}$ y Fe, además de $\mathrm{S}$ y trazas de Mn y Ti. 
En algunas ocasiones es de destacar la existencia de partículas de elevado peso atómico repartidas aleatoriamente por todas las capas de la costra mineral y cuya composición es básicamente de fosfato de cerio y lantano con trazas de Ag, U y Th.

También se ha podido estudiar la mineralización que se produce en las paredes de las células endolíticas mediante la observación comparada de imágenes, empleando electrones secundarios y retrodispersados. Este tipo de observaciones ayudan a comprender la implicación de las microalgas (principalmente clorofíceas sarcinoides) en la formación y mantenimiento de estas concreciones carbonatadas.

Las concreciones nodulares fueron también analizadas a partir de las correspondientes láminas delgadas. Presenta una composición similar a las concreciones planas, es decir de carbonato cálcico con partículas diferenciadas de silicato alumínico magnésico con azufre, cloro y potasio. En determinados casos se ha observado la presencia de arsénico, plomo y estaño, que acompaña a los silicatos de aluminio, magnesio, manganeso, potasio, titanio, fosforo y calcio (Bolívar Galiano y Sánchez Castillo, en prensa).

\section{B) Ficodeterioro de tipo físico}

Las algas que crecen en nuestros monumentos pueden actuar mecánicamente sobre los materiales:

I. Favoreciendo la gelifracción, a causa de la retención de agua por parte de las algas, en aquellas zonas donde se produzcan heladas en invierno.

2. Por formación de polímeros extracelulares (vainas), que por su gran higroscopicidad cambian bruscamente de volumen. En nuestros estudios se ha observado que ciertas especies (Phormidium favosum) poseen una vaina más mucosa cuando se encuentran en superficie que cuando ocupan capas internas de la pátina algal. Las diatomeas como Gomphonema olivaceum, también producen tubos mucilaginosos, que usan para fijarse al sustrato, contribuyendo a la formación de costras minerales.

3. Elevando considerablemente la porosidad de la superficie del material, lo cual favorece la retención de agua y por tanto su colonización por especies algales de mayores requerimientos hídricos. Este proceso es facilitado por la deposición de carbonatos porosos que tienen una estructura travertínica.

\section{C) Ficodeterioro de tipo químico}

La acción química de las algas sobre los monumentos es el tipo de deterioro más estudiado y se produce como consecuencia de las reacciónes bioquímicas y fisiológicas de las algas y sus organismos simbiontes. Serían:

I. Excreción de ácidos orgánicos (pirúvico, glicólico, láctico, acético, alfa-cetosuccínico, alfa-cetoglutárico) como resultado de los procesos de respiración, en la mayoría de las algas y con finalidad penetrante en especies euendolíticas como Hyella fontana.
2. Excreción de polisacáridos de acción quelante, que producen la disolución y acomplejamiento de los metales y su posterior transporte por la red capilar del mármol (Foto 5).

3. La variación del pH provocada por el metabolismo fotosintético y el incremento de la concentración de $\mathrm{CO}_{2}$ que producen en el medio las algas, son los desencadenantes químicos de la precipitación y agregación de partículas de carbonato cálcico (Foto 6).

4. Por sustentación de comunidades saprófitas de metabolismo muy corrosivo (acción sinérgica; Foto 7).

- bacterias heterótrofas que viven de los polímeros extracelulares que las algas producen. Aportan sustancias corrosivas que causan pérdidas de material en superficie y en profundidad. En este trabajo, mediante cultivo líquido se ha detectado la presencia del género Caulobacter fijado a las vainas vacías de Phormidium o formando rosetas.

- bacterias purpúreas del ciclo del azufre (familia Chromatiaceae), que contribuyen a la producción de ácido sulfúrico y por tanto de costras sulfatadas. En cultivo líquido enriquecido se ha encontrado el género Chromatium.

Foto 4: Patio de los Arrayanes en la Alhambra. Algas verdes y hongos en el enlucido (izquierda) y líquenes crustaceos en el zócalo cerámico (derecha)

Foto 5: Fotografía al Microscopio Electrónico de Barrido (MEB) donde se observa el efecto de las vainas polisacarídicas en la materia mineral.

- hongos que aprovechan la materia orgánica aportada por las comunidades algales (especialmente en las comunidades denominadas tapetes). La especie más frecuentemente encontrada ha sido Torula sp.

- briófitos, que también viven asociados a las algas en determinados biotopos (muros y percoladuras umbrías) al igual que ocurre en las tobas de ambientes naturales. La especie más característica es Gymnostomun calcareum.

La relación entre las algas y los demás organismos que forman parte de las comunidades fito-microbianas está aún poco estudiada (Parker y Bold, 1961). En nuestros estudios se ha observado que la aparición de bacterias purpúreas del azufre en las costras minerales, sólo se produce cuando las algas han formado, al menos, 8 capas fico-cristalinas alternadas que garantizan las condiciones anaerobias del medio que requieren estas bacterias cromatiáceas.
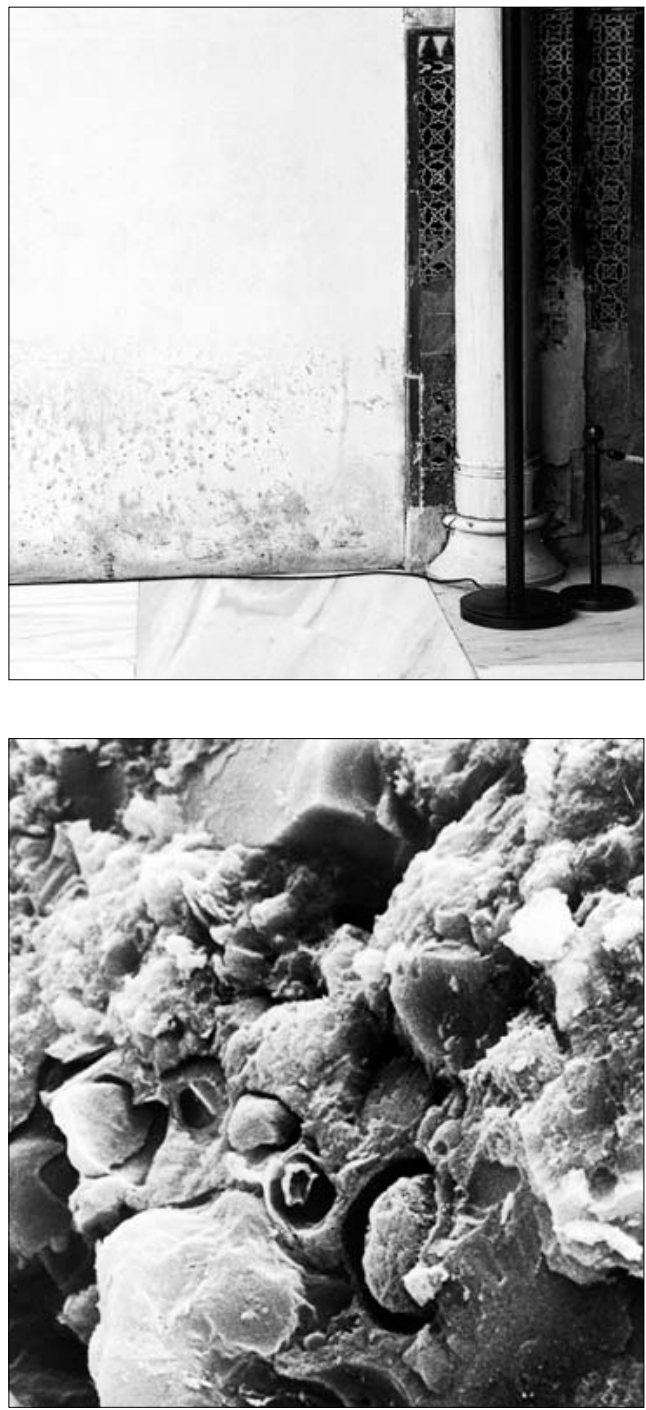
4

\section{Catalogación de las algas}

El estudio descriptivo y taxonómico de los organismos es importante en biodeterioro, por ser la única forma de normalizar y comparar las investigaciones llevadas a cabo en los diversos monumentos y campos de estudio. Sólo de esta forma se podrán extrapolar y contrastar resultados y así obtener conclusiones.

De todas formas, como en el estudio del ficodeterioro lo más importante es la aplicación de los conocimientos a la práctica de la conservación, hemos creído conveniente simplificar la compleja ordenación sistemática, realizando una primera agrupación por tipos biológicos (que puede resultar más útil y comprensible para una persona no especializada en el campo de las algas).

La clasificación por biotipos no es muy corriente en algología y sólo es planteada por determinados investigadores (Margalef, 1947; Reynaud en Meeting, 1991). En nuestro caso,

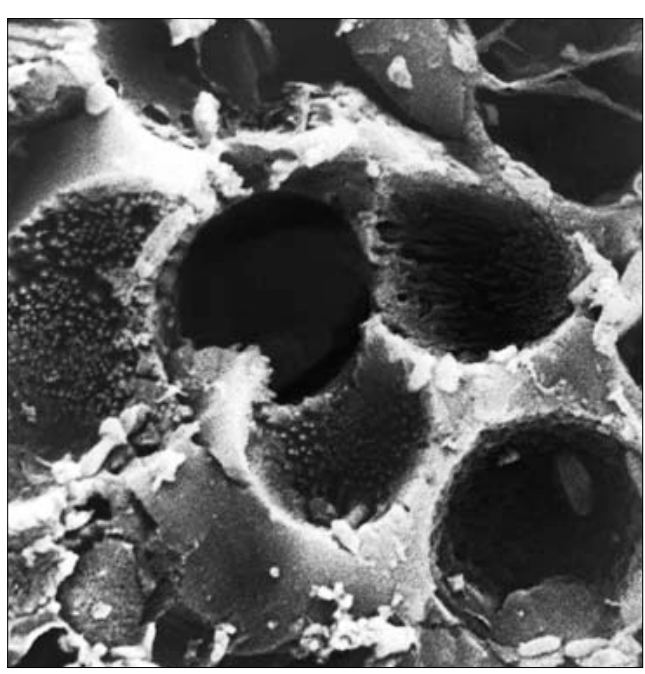
tiene connotaciones metodológicas que favorecen la comprensión de estas comunidades tan complejas y sus posibles mecanismos de deterioro. Además, se ha realizado una identificación taxonómica lo más completa que ha sido posible. Esto nos permite establecer comparaciones con los organismos identificados en otros lugares de características similares.

Como ya se ha dicho, apenas se han realizado

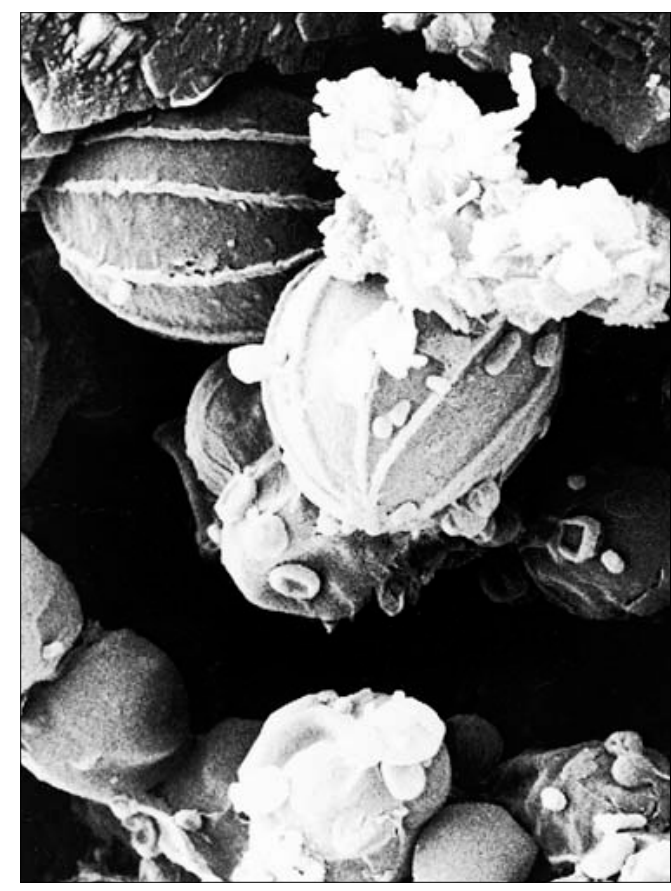

trabajos de biodeterioro o ficología en fuentes monumentales. En cambio, si se han realizado en mayor número, aunque no suficientes, sobre piedra de catedrales y otros monumentos (que carecen de los biotopos sumergidos y anfibios de las fuentes). El estudio del biodeterioro de las fuentes puede ser aún más complejo, por la mayor riqueza en biotopos, que amplía enormemente el número de especies posibles, y por ser obras sometidas a causas de deterioro muy intensas, como la acción continuada del agua (por esta razón se emplean piedras de gran resistencia, como el mármol, para la construcción de fuentes).

\section{ESTUDIO DE LOS AGENTES DE DETERIORO}

Los estudios que hemos realizado en diversos monumentos sobre biodeterioro algal, han revelado la presencia de más de un centenar de especies, de las cuales la mayor parte son algas verdes y cianobacterias, destacando también numerosas especies de diatomeas y alguna euglenofícea y criptofícea.

Las diferentes especies estudiadas pueden agruparse en 5 biotipos que de alguna forma, se pueden relacionar con un mayor o menor capacidad de deterioro.
I Unicelular
II Agregado gelatinoso
III Agregado no gelatinoso
IV Estructura pseudoparenquimática
$\checkmark$ Filamentos (con y sin vaina)

Los biotipos algales aquí descritos pueden encontrarse en cada uno de los tres grandes grupos de algas estudiados. Las comunidades que éstas constituyen se desarrollan en determinados lugares de los monumenotos (biotopos), los cuales vienen definidos fundamentalmente por el tipo de aporte hídrico que reciben.

\section{Catalogación del los organismos}

\section{BIOTIPO I: Unicelular}

Constituyen, desde un punto de vista morfológico los organismos fotosintéticos más simples que pueden desarrollarse en cualquier ambiente. Sus representantes pueden presentar movimiento activo o pasivo y no muestran fases de vida vegetativa adheridas al sustrato. Cuando constituyen comunidades monoespecíficas, estas no son mas que suspensiones de células sin ningún tipo de fijación al sustrato.

En las obras estudiadas hemos encontrado organismos unicelulares pertenecientes a las divisiones Chlorophyta (algas verdes) y Bacillariophyta (diatomeas). 


\section{Algas verdes}

\section{a) Algas verdes móviles}

Género Chlamydomonas. Sus representantes varían desde esféricos hasta elipsoidales o cilíndricos, caracterizándose por la presencia de dos flagelos apicales que dotan a la célula de movimiento propio. Es una especie típicamente acuática, que consigue colonizar sustratos anfibios y aéreos produciendo gelatina y pasando a una fase de reposo, de aspecto gelatinoso durante la cual es mucho más patente y puede ser un importante agente de deterioro estético. Se ha encontrado principalmente durante primavera y verano.

\section{b) Algas verdes inmóviles}

Género Chlorococcum. Células solitarias, esféricas a veces elipsoidales, con pared celular rígida, no deformable. Es un género difícil de caracterizar, ya que existen numerosos géneros de morfología circular. Las células de resistencia presentan un intenso color anaranjado o bermellón. En la Fuente de los Leones de la Alhambra, se ha encontrado, constituyendo comunidades casmolíticas en las grietas de las patas de varios leones, durante la primavera.

Género Scotiellopsis. Células desde elipsoidales hasta ovales, circulares en sección transversal. La pared celular se encuentra engrosada, constituyendo costillas longitudinales que recorren la célula de polo a polo. Se caracterizan por tener forma de limón asimétrico (Foto 7). Los ápices suelen estar ligeramente curvados. Como su nombre indica habita biotopos aéreos o anfibios, de sustrato terroso.

\section{c) Algas verdes inmóviles}

Género Cosmarium. Sus representantes son fácilmente caracterizables, ya que su célula presenta un estrangulamiento central que la divide en dos partes simétricas: hemisomas. Los hemisomas, sin prolongaciones, pueden presentar una enorme variabilidad en su ornamentación.

\section{Diatomeas}

Constituyen uno de los grupos más característicos de algas (Fotos 8 y 9). La presencia de una cubierta silícea (frústulo) que rodea la célula, así como su coloración desde verde-amarillenta, amarilla, dorada hasta marrón, permite una fácil caracterización de sus representantes. Su clasificación, incluso a nivel genérico, requiere un tratamiento específico que elimine toda la materia orgánica y permita, tras su inclusión en una resina específica observar la ornamentación del frústulo.

\section{a) Diatomeas céntricas}

Género Cyclotella. Además de la morfología circular que muestran sus valvas, este género se caracteriza por presentar dos zonas bien definidas en su superficie valvar. La zona marginal muestra una ornamenta- ción estriada, mientras que el centro de la valva no presenta ningún tipo de ornamentación. El aparato plastidial está constituido por numerosos plastos parietales discoidales. La mayoría de las especies presentan vida aislada, aunque algunas pueden formar cadenas.

\section{b) Diatomeas pennadas}

Género Achnanthes. Es el género más característico de uno de los ordenes de diatomeas pennadas. Suelen diferenciarse fácilmente por poseer el frústulo curvado.

Género Amphora. Sus representantes muestran una zona dorsal convexa formada por una serie de bandas intercalares que cierran la estructura frustular. Sólo se ha detectado la presencia de una especie: A. perpusilla (Foto 8 ). Sus poblaciones están formadas por células de pequeño tamaño $(9.5-15$ × 4.5-6 $\mu \mathrm{m}$.). Patrick y Reimer (1975) la consideran endolítica.

Género Cocconeis. Células elípticas u oblongas que viven adheridas al sustrato, generalmente vegetal. La ornamentación, de naturaleza lineada, forma estrías longitudinales que recorren toda la valva.

Género Cymatopleura. Células elípticas con la superficie valvar ondulada como consecuencia se producen fuertes elevaciones que aparecen a modo de costillas. La zona central puede presentarse claramente ensanchada o estrangulada. Las poblaciones estudiadas son C. solea, de 59-88 x 15-29 $\mu \mathrm{m}$. La zona periférica presenta pequeñas costillas marginales.

Género Cymbella. Células de forma semicircular, destacando un margen dorsal convexo y otro ventral plano o ligeramente convexo.

Género Denticula. Valvas lanceoladas, de pequeño tamaño. Es patente la existencia de costillas que solo alcanzan la mitad de la anchura de la valva. Es frecuente observar pequeñas cadenas de células.

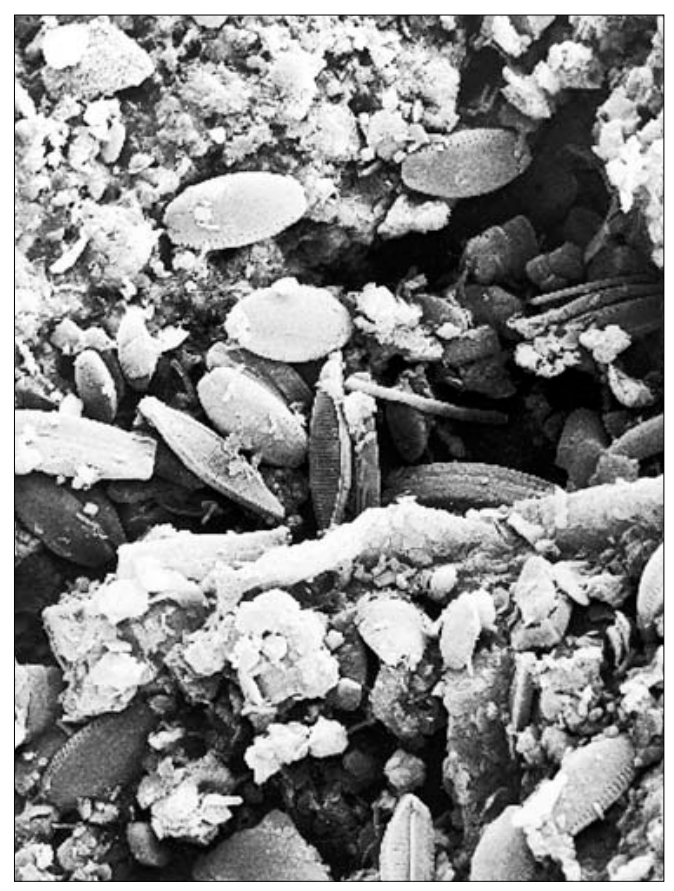

Foto 8: Microfotografía al MEB mostrando dos especies de diatomeas que crecen en costras mineralizadas; Amphora perpusilla (de forma ovalada) y Nitzschia sp. (fusiforme). 
$\longleftarrow$
$\square$
$\square$

Género Diploneis. Sus valvas son de contorno elíptico (en algunas especies estranguladas en el centro). Las estrías son de estructura areolada, muy patentes, dándole a la valva un aspecto refringente. $D$. ovalis es una especie relativamente grande, $34-42 \times 17-21 \mu \mathrm{m}$ que suele desarrollarse en ambientes aéreos.

Género Epithemia. Valvas convexas en la zona dorsal con estriación convergente en el centro de la valva. La población encontrada se desarrolla de forma epíita sobre filamentos del alga verde Cladophora glomerata.

Género Gyrosigma. Células lanceoladas con los ápices curvados en sentido opuesto y una típica ornamentaciónr reticulada. No aparece con frecuencia y cuando lo hace no es muy abundante; posee un tamaño considerable: $112-120 \times 14-16$.

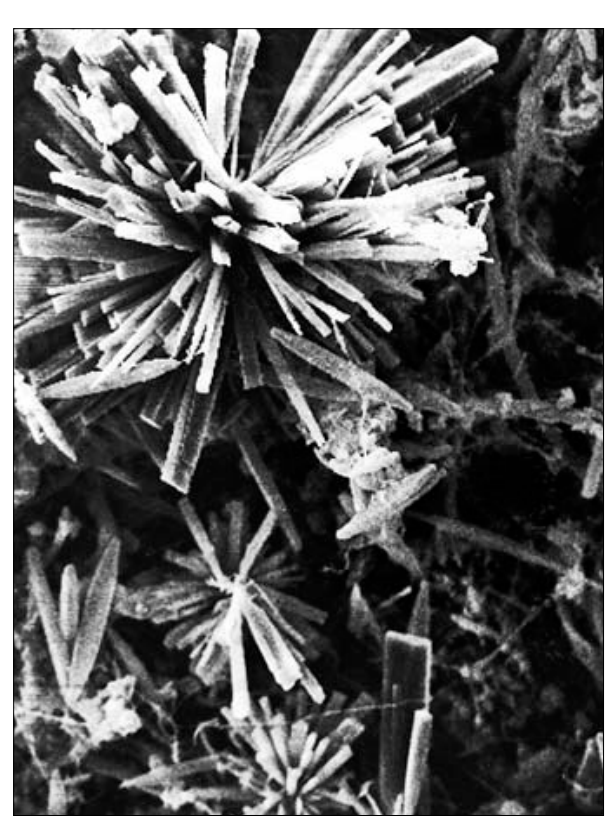

Foto 9: Ramilletes de diatomeas epilíticas (Nitzschia sp.) observados al MEB en una muestra tomada en una fuente monumental.
Género Navicula. Valvas de morfología lanceolada y bisimétrica. A ambos lados del rafe se desarrolla un sistema de estrías cuya morfología y densidad son la base para la caracterización específica. Constituye uno de los géneros de diatomeas más ampliamente distribuidos.

Género Nitzschia (Fotos 8 y 9). Sus distintas especies presentan una gran variabilidad de formas y tamaños: linear, elíptica, fusiforme (Foto 8), e incluso de biotipos: unicelular, agrupación no gelatinosa y filamentos sin vaina. En los grandes ejemplares son patentes los puntos marginales (fíbulas) además de las estrías que atraviesan de margen a margen la totalidad de la célula. Existen especies consideradas como subaéreas. Otras son especies unicelulares y móviles con forma acicular que se caracterizan por formar ramilletes de células unidas entre sí y al sustrato por uno de los ápices (Foto 9).

Género Rhopalodia. Su visión comisural es muy característica, presentando ambos lados convexos. Las valvas se encuentran recorridas por gruesas estrías entre las que se disponen series de areolas. Son especies frecuentes en piedra rezumante.

Género Surirella. Sus valvas están recorridas por gruesas costillas que se interrumpen en la zona central, dando lugar a un canal central. Las costillas pueden prolongarse hacia el exterior dando lugar a una zona marginal ligeramente alada. Es un género propio de ambientes sometidos a procesos de desecación.

Género Synedra. Incluye un conjunto de especies, de aspecto grácil, en forma de aguja y con estrías paralelas que recorren toda la valva, dibujando una pequeña área hialina en el centro.

\section{Euglenoficeas}

Género Euglena. Células móviles, libres, fusiformes o globulosas de sección transversal circular. Estas células solitarias nadan libremente gracias a un flagelo ondulado que surge de la citofaringe. La cutícula está a menudo ornamentada por estrías helicoidales más o menos marcadas. Se desarrollan en determinadas épocas del año en algunas fuentes monumentales.

\section{BIOTIPO II: Agregados glatinosos}

Este biotipo está constituido fundamentalmente por cianobacterias. El origen de estas masas se encuentran en las mismas células que segregan sustancias de naturaleza polisacarídica que rodean a las células en forma de vaina.

\section{Cianobacterias}

\section{a) Células esféricas o elípticas en matríz amplia}

Género Aphanothece. Células generalmente elipsoidales, en ocasiones cilíndricas. El conjunto de las células se encuentran rodeadas por una masa mucilaginosa homogénea, no estratificada.

Género Gloeocapsa. Sus células se encuentran rodeadas por vainas concéntricas, estratificadas. El color de la vaina es muy variable desde hialo hasta negruzco. Las agrupaciones suelen presentar una morfología mucosa, irregular.

\section{b) Agregados celulares compactos}

Género Chlorogloea. Las células son esféricas o irregulares, más o menos angulosas, a veces con una ordenación longitudinal sobre todo en las zonas marginales. En el interior del talo se pueden diferenciar pequeños paquetes de células, rodeados por vainas o muy compactadas. Los bordes de las agrupaciones aparecen de una tonalidad más oscura que el resto.

Género Chroococidiopsis. Las células y/o grupos de células se encuentran rodeados por una vaina amarillamarrón-negruzca. Las poblaciones estudiadas presentan un diámetro celular entre 2-4 $\mu \mathrm{m}$.

Género Nostoc. Sus especies constituyen una de las agrupaciones gelatinosas más fácilmente diferenciables. Sus células se ordenan en filamentos que se rodean de vainas, por lo general amplias, que a su vez quedan englobados en una matriz externa, constituyendo amplias masas mucosas. Estas colonias de abundante mucílago, crecen fácilmente en la mayor parte de los cultivos que hemos realizado con el medio CHU-I0.

\section{Diatomeas}

Género Gomphonema. Bacilariofícea pennada que se caracteriza por fijarse al sustrato mediante tubos mucilaginosos que parten de un extremo de la célula. Da lugar a agregados de consistencia viscosa y coloración ocrácea, que en algunos lugares adquieren gran tama- 
ño y forma globosa (en la taza de la Fuente de los Leones hasta $2.5 \mathrm{~cm}$ de diámetro).

\section{Algas verdes}

Género Palmella. Forma colonias gelatinosas que a menudo se aprecian macroscópicamente. Las células pueden ser elipsoidales o esféricas están dispuestas en grupos de dos o cuatro dentro de un gel hialino y homogéneo.

\section{BIOTIPO III: Agregados no gelatinosos}

Este biotipo está integrado fundamentalmente por especies de algas verdes. La unión se produce generalmente por contacto de sus paredes celulares, dando lugar a agrupaciones de morfología muy característica. En este biotipo se distinguen varios grupos, dependiendo de su forma de asociación.

\section{Cianobacterias}

Género Myxosarcina. Forman agrupaciones constituidas por células densamente empaquetadas y de contorno anguloso, observándose ciertas regularidades en su ordenación. Las agrupaciones permanecen unidas al sustrato, disgregándose en la madurez. La distinción de las especies se realiza fundamentalmente por el tamaño.

\section{Algas verdes}

I. Cenobios y otras agrupaciones regulares. Los cenobios son agrupaciones celulares caracterizadas por proceder todas las células de la misma generación. Por lo general suelen ser grupos celulares de reducido número (4-16), estas unidades discretas pueden agregarse dando lugar a amplias masas celulares.

Género Scenedesmus. Sus células son de morfología ovoide, elipsoidal o piriforme y constituyen cenobios de forma lineal, de 4 u 8 células, a veces incluso 16 - 32. En ocasiones los cenobios hijos pueden unirse mediante fragmentos de las paredes celulares, dando lugar a grandes formaciones. Han aparecido varias especies del género en las obras estudiadas. De forma esporádica pueden aparecer representantes de los géneros Pediastrum y Pandorina ya que sus cenobios son normalmente planctónicos. El primero es inmóvil y el segundo móvil mediante flagelos (dos por célula).

Género Tetracystis. Sus células vegetativas pueden presentarse de forma aislada o constituyendo grupos de 4 u 8 dispuestas tetraédricamente en grupos globulosos. En general son especies frecuentes en ambientes anfibios y acuáticos.

Género Poloidion. Sus células y agrupaciones tetraédricas recuerdan a las especies de Apatococcus. Se caracterizan morfológicamente por la existencia de engrosamientos polares en la pared celular. Las poblaciones de este estudio habitan sustratos aéreos o anfibios con baja intensidad luminosa, a menudo en capas endolíticas.
2. Grupos sarcinoideos. Son agrupaciones de gran número de células, fuertemente compactadas. Constituyen una fase previa a las estructuras parenquimáticas diferenciadas.

Género Chlorosarcinopsis. La morfología básica de sus especies son paquetes de células de ordenación más o menos cúbica y muy compactadas. La fuerte compresión a la que se encuentran sometidas sus células en condiciones endolíticas, es la responsable de que estas aparezcan claramente poligonales cuando se rompe la unión de las mismas mediante disgregación mecánica. Sólo se ha diferenciado una especie, presentando una considerable amplitud ecológica, desde zonas anfibias hasta otras claramente sumergidas.

3. Agregados polares. Se incluyen células que presentan una clara diferenciación ápice-base, siendo todas ellas células fijas y adheridas por uno de sus extremos celulares. Dentro de este grupo se incluyen especies tanto de diatomeas como de algas verdes.

Género Fernandinella. Sus células presentan una porción basal por la que se unen al sustrato. En nuestros trabajos se ha observado unida a formaciones cristalinas por su zona basal, dando lugar a grandes masas de células. Del mismo modo suele aparecer adherida a los talos de Chamaesiphon y a los esporangios terminales de Pleurocapsa.

\section{BIOTIPO IV: Estructuras Pseudoparenquimáticas}

Las células de las especies de este biotipo se unen inicialmente constituyendo cortos filamentos polares. Por su tipo de crecimiento, los filamentos se disponen uniéndose en paralelo, dando lugar a estructuras compactas tridimensionales donde por lo general puede reconocerse su alineación longitudinal. Sus representantes son cianobacterias y algas verdes, con una enorme capacidad de colonización, dando lugar a importantes formaciones, por lo general bastante homogéneas. De menor a mayor complejidad podemos considerar dos subtipos: filamentos erectos fusionados (Chamaesiphon, Pleurocapsa, etc.) y filamentos independientes e incrustantes erectos o rastreros, generalmente de disposición longitudinal o radial, que suelen dar lugar a estructuras endolíticas. (Hyella, Gongrosira, etc.).

\section{Cianobacterias}

Género Chamaesiphon. Sus representantes se caracterizan por la formación de exosporas, las cuales suelen permanecer sobre la célula que las forman, produciéndose de esta forma el crecimiento del filamento. Las células basales presentan una vaina propia denominada vagina, con naturaleza mucosa, que contribuye de forma notable a compactar las formaciones de las que forma parte. La coloración, muy variada, se debe al efecto aditivo de estas vainas.

Género Pleurocapsa. Las especies incluidas en este género muestran una fuerte variabilidad morfológica, ya que pueden aparecer desde formaciones, más o menos 
sarcinoideas, hasta otras con una ordenación filamentosa claramente establecida. Presentan rizoides que se unen al sustrato, e incluso pueden penetrarlo, comportandose en ocasiones como organismos endolíticos.

Género Hyella. Sus representantes forman filamentos ramificados. El grado de compactación de los filamentos no llega a ser tan intenso como en Pleurocapsa. La parte basal de los filamentos se comportan como rizoides que llegan a perforar la piedra monumental.

\section{Algas verdes}

Género Apatococcus. Sus células presentan una ordenación en paquetes cúbicos o irregulares, a veces algunas células se alinean dando lugar a grupos filamentosos. Las células presentan una morfología globulosa y son de pequeño tamaño.

Género Gongrosira. Este género se caracteriza por presentar una porción basal rastrera y otra erguida. Los filamentos se entrelazan fuertemente entre sí dando lugar a una estructura pseudoparenquimática que recubre la piedra. Hemos diferenciado cuatro especies que comprenden toda la variabilidad genérica.

Género Leptosira. Constituyen verdaderos filamentos, dando lugar a pequeñas agrupaciones que crecen de forma almohadillada sobre la piedra. Sus células son globulosas toneliformes, a veces ligeramente cilíndricas.

Género Pleurastrum. Sus filamentos son considerablemente reducidos, uniseriados, concentrándose densamente en la parte central de la agrupación, quedando libres solamente la zona apical de los mismos. Sus células varían desde cilíndricas hasta subglobosas. Se han diferenciado dos especies que se desarrollan fundamentalmente en ambinentes aéreos o anfibios.

Género Pseudopleurococcus. Posee características ecológicas y morfológicas similares a Pleurastrum, diferenciándose por la presencia de ramas rastreras y erectas.

\section{BIOTIPO V: Filamentos}

\section{a) Filamentos sin vaina}

En este grupo se encuentran representados biotipos de distintos grupos taxonómicos. Sus especies se desarrollan preferentemente en sustratos pétreos sumergidos.

\section{Cianobacterias}

Son pocas las especies que presentan este biotipo aunque en ocasiones dan lugar a importantes crecimientos.

Género Oscillatoria. Sus tricomas están formados por células de morfología variable, desde cilíndricas hasta discoidales. Su movimiento por reptación les hace ser importantes en la colonización de superficies pétreas con humedad más o menos permanente.

\section{Diatomeas}

Género Diatoma. Sus células son elipsoidales, recorridas por costillas transversales patentes a lo largo de toda su valva. Sus filamentos son en forma de zig-zag, aunque en ocasiones pueden encontrarse células aisladas.

Género Fragilaria. Está bastante extendido en estos ambientes, principalmente en superficies sometidas a la acción de excorrentías de agua.. Normalmente aparece, en gran número fijada sobre filamentos de Lynbya o Phormidium.

Género Melosira. La superficie valvar es totalmente lisa. Las células se unen formando filamentos que pueden llegar a ser de gran longitud. El aspecto macroscópico es el de mechones de finos filamentos de color marrón oscuro.

El género Navicula tiene un representante que puede formar cadenetas más o menos largas.

Dentro del género Nitzschia, anteriormente citado, existe una especie muy frecuente caracterizada por formar cadenetas de células unidas por sus valvas longitudinalmente.

\section{Algas verdes}

Género Cladophora. Sus especies presentan un modelo de ramificación muy característico, así como una pared celular estratificada de gran tamaño. La parte basal de los filamentos se convierten en rizoides con capacidad de penetrar en la piedra. Esta alga se desarrolla especialmente en ambientes acuáticos de curso rápido, dando lugar a masas de ovas de gran tamaño.

Género Cylindrocapsa. Se caracteriza por presentar una pared celular gruesa y estriada.. A menudo aparece en fase unicelular engrosando su pared, redondeándose y volviéndose hialino su citoplasma. Habitan superficies aéreos o anfibios.

Género Microspora. Alga que presenta células cuadrangulares. Son muy patentes las piezas en "H" en los extremos de los filamentos. Pueden dar lugar a quistes de color pardo negruzco, que suponen una gran adaptación a los ambientes cambiantes (anfibios).

Género Oedogonium. Filamentos no ramificados que suelen presentar anillos de crecimiento y repliegues en las uniones celulares. Terminan dando lugar a "ovas" y suelen presentar partículas y diatomeas adheridas a su pared celular.

Género Spirogyra. Alga cuyos filamentos presentan células cuadradas y rectangulares. Son especies típicamente acuáticas que viven en ambientes sumergidos y terminan originando "ovas" o "camas de rana". En nuestros estudios se han encontrado filamentos en copulación, con zigotos en fase de maduración.

Género Stigeoclonium. Alga filamentosa con ramas que se atenúan en los extremos. Las células suelen ser más largas que anchas. Habita biotopos sumergidos y aparece con relativa frecuencia en sustratos ma- 
duros. Es frecuente en algunas fuentes de la Alhambra, durante los períodos sin tratamiento.

Género Ulothrix. Filamentos no ramificados de células cuadrangulares. Suelen aparecer en superficies anfibioas.

Género Zygnema. Clorofícea filamentosa que nunca presenta ramificaciones. La especie encontrada en la Fuente del Cuarto Dorado presenta células rectangulares con dos plastos estrellados, uno en cada extremo de la célula.

\section{b) Filamentos con vaina}

En este subgrupo se incluyen exclusivamente cianobacterias. La presencia de vainas confiere a estos organismos una gran capacidad de compactación y aglutinación, de forma que participan en gran medida en aquellas comunidades capaces de acumular materia mineral. Por lo general, se unen por sus vainas dando lugar a formaciones macroscópicas densas y postradas (especies de Phormidium); aunque también pueden ser más laxas (especies de Lyngbya) o más o menos erectas (especies de Symploca).

Género Calothrix. Es uno de los táxones filamentosos más características de las cianobacterias, ya que sus filamentos son polares. La parte basal, la más gruesa, presenta un heterocisto a partir del cual se produce una disminución del tamaño de las células vegetativas, acabando en células cilíndricas, muy finas, en ocasiones en forma de pelo. El conjunto del tricoma se encuentra rodeado por una vaina.. Presentan una ecología bastante definida, comportándose como especies sumergidas, principalmente en las paredes internas de las fuentes monumentales.

Género Lyngbya. Sus tricomas se encuentran rodeados por vainas, por lo general consistentes. Las células son muy variables en tamaño y la vaina puede presentar distinta coloración. No suelen formar grandes agrupaciones, viviendo junto a otras algas.

Género Microcoleus. Esta cianobacteria se caracteriza por presentar varios tricomas por vaina. Es un género típico de ambientes aéreos que aparece en las superficies de menor aporte hídrico en las fuentes. La vaina mucosa común que presentan suele aglutinar gran cantidad de partíiculas.

Género Phormidium (Foto 10). Sus tricomas se encuentran rodeados por vainas particulares, en este caso de naturaleza mucosa, siendo éste el carácter que lo separa de Lyngbya, sin embargo esta propiedad de su vaina hace que sus especies formen talos laminares mucosos o gelatinosos.

Género Schizothrix. En este género se disponen varios tricomas en el interior de una vaina común, generalmente gruesa. Todos ellos se desarrollan en ambientes susceptibles de desecación.

Género Symploca. A excepción de la presencia ocasional de falsas ramificaciones, los caracteres propios de este género son muy similares a Phormidium. Su dife- renciación se realiza a nivel de los caracteres macroscópicos. Se caracteriza por la formación de mechones perpendiculares al sustrato; éstos son formados por la parte apical de los filamentos, dando un aspecto muy característico a sus agrupaciones macroscópicas.

Género Tolypothrix. Esta alga verde azulada presenta filamentos con falsas ramificaciones formando cojinetes y mechones erguidos. La especie encontrada aparece en los muros de ladrillo y argamasa de los patios umbrios. Crece en los cultivos sólidos con facilidad.

\section{Mecanismos de ficodeterioro e importancia de los biotipos}

El poder deteriorógeno de las algas y el resto de los organismos vivos sobre la piedra ha sido hasta hace poco subestimado y muy discutido, principalmente por científicos de disciplinas no biológicas. En cambio de un tiempo a esta parte, especialistas de reconocido prestigio en el estudio del deterioro de la piedra monumental (Esbert et al., 1980; Ortega-Calvo et al, 1993; etc.), afirman que éstos ejercen una acción no despreciable, y en algunos casos determinante, en la alteración general del material rocoso.

Las algas endolíticas, sensu Golubic et al. (1981), por su gran capacidad de colonización se convierten en uno de los más serios agentes de biodeterioro en piedras monumentales (Anagnostidis et al, 1983; Danin y Caneva, 1990). De hecho, en la Alhambra son

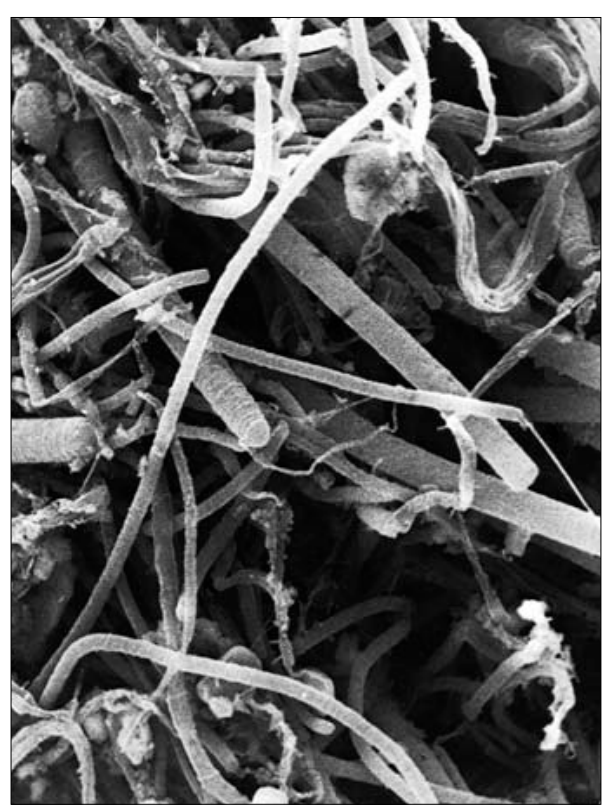
este tipo de algas las que resisten los intensos tratamientos por quedar protegidas, bajo el mineral, de la acción del biocida aplicado. Sin embargo, en los lugares donde el agua no es un factor limitante, como en las fuentes ornamentales, muchas especies epilíticas pueden crecer en la superficie de la piedra. Estas producen comunidades macroscópicas, dentro de las cuales pueden desarrollarse otros organismos, como los líquenes, musgos y plantas vasculares (normalmente en los biotopos más aéreos). Estos nuevos crecimientos, que podrían ser incluso más dañinos para la buena conservación de las fuentes, han sido estudiados en otros lugares por Giacobini et al (1987), Ricci et al (1988), García-Rowe y Sáiz-Jiménez (1991), entre otros.

Uno de los principales problemas causados por las algas se refiere a los problemas de carbonatación, producidos como consecuencia de la retirada del anhídrido carbónico durante la fotosíntesis y precipitación de carbonatos (Margalef, 1985). Todos los grupos taxonómicos son capaces de producir este fenómeno,
Foto 10: Microfotografía de cianobacterias filamentosas con vaina (Phormidium, etc.) 
pero es especialmente patente en algas verdes y cianobacterias. Este fenómeno ha sido ampliamente documentado en aguas corrientes de distintos países (Fjerdingstad, 1957), sin embargo no encontramos en la bibliografía documentación en fuentes, tanto naturales como artificiales. Las pocas referencias existentes (Fjerdingstad, I.c.) consideran que estas alteraciones están ligadas a la presencia de Phormidium incrustatum en ríos y lagos, acompañado por distintas especies de Schizothrix, Gongrosira, Rivularia y Calothrix, que son otros táxones que participan en la formación de estas estructuras carbonatadas. La presencia de cianobacterias y algas verdes "chaetophorales" en nuestras fuentes prueban el origen biológico de estas alteraciones, las cuales se producen especialmente en zonas donde se desarrollan especies de Phormidium y algas verdes (Chlorosarcinopsis, Leptosira, etc.).

Las algas "a priori" más dañinas, serán aquellas que presenten agrupaciones compactas (gelatinizadas o no) tales como sarcinas (paquetes) y filamentos aglutinados. En este contexto, Friedmann (197I) afirma que el volumen de las paredes celulares de las algas verde-azuladas (cianobacterias) puede incrementar veinte veces su valor, mediante la imbibición de agua. El poder biodeteriorógeno de este tipo de algas, es- pecialmente las filamentosas con vaina, han sido observado en otros ecosistemas. Ortega-Calvo et al. (1990) estudiando el deterioro mecánico en piedra de catedrales han observado que las formas filamentosas forman la mayor parte de la biomasa. Éstos últimos afirman que todos los filamentos que han estudiado presentan envuelta gelatinosa, la cúal contribuye a la formación de masas apretadas en íntima relación con la superficie de la piedra.

Por tanto, aunque el grado de biodeterioro pueda depender del biotipo algal, que determina el poder de penetración e infiltración y la posterior proliferación masiva dentro de la costra mineralizada, el grado de desarrollo de la formación algal (pústula, película, tapete y estromatolito) puede dar lugar a distintas alteraciones, aunque sus células presenten la misma biotipología (Bolívar y Sánchez-Castillo, 1995). Además, se constata que en general, cuanta más variedad de biotipos exista en una formación algal, esta tendrá mayor capacidad de alterar el sustrato, ya sea modificando o imposibilitando su percepción original (deterioro funcional directo), dando lugar a costras minerales (deterioro funcional indirecto) o penetrando activamente en dicho sustrato (deterioro material).

\section{Referencias bibliográficas}

ALBERTANO, P.; LUONGO, L. \& M. GRILLI CAIOLA (199|a): Influence of different ligths on mixed cultures of Microalgae from ancient frescoes. International biodeterioration, 27 (I): 27-29.

ALBERTANO, P.; LUONGO, L. \& M. GRILLI CAIOLA (199|b): Observations on cells structure of microorganisms of an epilithic phototropic community competing for ligth. Nova Hedwigia, 53 (3): 369-381.

ANAGNOSTIDIS, K; ECONOMOU-AMILLI, A; ROUSSOMOUSTAKAKI, M (1983). Epilithic and chasmolithic microflora (Cyanophyta, Bacillariophyta) from marbles of the Parthenon (Acropolis-Athens, Greece). Nova Hedwigia, 38: 227-287.

BOLÍVAR GALIANO, F. C. (1994): Diagnosis y tratamiento del deterioro por microalgas en los Palacios Nazaries de la Alhambra. Editorial Univ. Granada. pp 246

BOLÍVAR, F. C. \& P. M. SÁNCHEZ CASTILLO (1995): Preliminary results on the study of the algal biodeterioration within the Alhambra (Granada, Spain): 210-216. In: A. Bousher, M. Chandra \& R. Edyvean (eds). Biodeterioration and Biodegradation 9. Inst. Chem. Eng. Rugby. U.K. pp. 663.

BOLÍVAR, F. C. \& P. M. SÁNCHEZ-CASTILLO (1996): Evaluación de los tratamientos algicidas realizados en la Alhambra. In: E. Sebastián, I.Valverde \& U. Zezza (eds). Restoration of Buildings and Architectural Heritage. Ed. CEHOPU-CEDEX \& Univ. Granada.

BOLÍVAR, F. C. \& P. M. SÁNCHEZ-CASTILLO (1997): Biomineralization processes in the Fountains of the Alhambra (Granada, Spain). Int. Biodeterior. \& Biodegrad. pp 205-215.
BRACHERT, TH. (1990): La patina nel restauro delle opere d'arte. Nardini editore. Edit. Ciudad. 237 pag.

DANIN, A. \& G. CANEVA (1990). Deterioration of limestone walls in Jerusalem and marble monuments in Rome caused by Cyanobacteria and Cyanophilous lichens. International Biodeterioration, 26: 397-417.

ESBERT, R. M, J. ORDAZ y L. M. SUÁREZ DEL RÍO (1980): La durabilidad de los materiales calcáreos como piedra monumental; pag 245-25।.

FJERDINGSTAD, E. (1957): A lime-incrusting alga community of a Danish Well. Rev. Algol., vol. 4: 246-248.

FOGED, N. (1976): Diatoms from the Alhambra, Granada, Spain. Nova Hedwigia, 27 (3/4): 88I-90।.

FOGED, N., (1983): Diatoms of fountains, reservoirs and some other humid and dry localities in Rome (Italy). Nova Hedwigia, 38: 433-470

FRIEDMANN, E. I. (197I): Light and seanning electron microscopy of the endolithic desert algal habitat. Phycologia, 10 (4): 4I I-428.

GARCÍA ROWE, J. y C. SÁIZ JIMÉNEZ (199|): Colonización y alteración de la piedra por líquenes, briófitos y plantas superiores en las catedrales de Salamanca, Sevilla y Toledo. Jornadas sobre Restauracion y Conservacion de monumentos. Madrid. Ed. I.C.R.B.C. Ministerio de Cultura. pag: 7I-79. 
GIACOBINI, C. y M. R. GIULIANI (1987): Analisi Biologiche. II restauro della "Barcaccia" in Piazza di Spagna. La Repubblica. Assesorato alla Cultura. Comune di Roma.

GIACOBINI, C., A. M. PIETRINI, S. RICCI y A. ROCCARDI (1987). Problemi di biodeterioramento. In: Materiali lapidei. Bolletino D'Arte. Suppl. 4I: 53-54.

GOLUBIC, S.; I. FRIEDMANN y J. SCHNEIDER (198I): The lithobiontic niche, with special reference to microorganisms. J. Sediment. Petrol., 51: 475-478.

GRILLI CAIOLA, M y P. ALBERTANO (1986): Indagine sulla flora algale di affreschi nell'ambiente. Scienza e Beni culturali. Convegno Bressanone. Ed: LPEP, pag: 696-697.

GRILLI CAIOLA, M; C. FORNI y P. ALBERTANO (1987): Characterization of the algal flora growing on ancient Roman frescoes. Phycologia, 26 (3): 387-396.

HERNÁNDEZ-MARINÉ, M; J. J. ORTEGA CALVO Y C. SÁIZJIMÉNEZ (1992): El microscopio electrónico de barrido como instrumento de estudio del biodeterioro de obras de arte. En: J. Vilches y A. López. Microscopía Electrónica 1992. Ed. Pub. Universidad de Cádiz; pag: 244-245.

MARGALEF, R. (1947): Limnosociología. Monogr. Ciencia Moderna, 10. Ed. Inst. Esp. Edaf. Ecol. y Fisiol. Vegetal, 4. Madrid. pp 93.

MARGALEF, R. (1983): Limnología. Ed. Omega S.A., Barcelona. I.010 pags.

METTING, B. (1991): Biological surface features of semiarid lands and deserts. In: Skujins, J. (Ed). Semiarid lands and deserts: soil resource and reclamation. Marcel Dekker, pag: 257-293.

NOGUEROL SEOANE, A \& A. B. RIFÓN LASTRA (1996). Aportación al conocimiento de la ficoflora epilítica en monumnentos del noroeste de España. Estudio del Monasterio de Samos (Lugo). Anales del Jardín Botánico de Madrid, 54(I): 37-42.

ORTEGA-CALVO, J. J.; M. HERNANDEZ-MARINÉ y C. SÁIZJIMÉNEZ (1990): Mechanical Deterioration of Building Stones by Cyanobacteria and Algae. 392-394. in: H.W. Rossmoore (ed). Biodeterioration and Biodegradation 8.Ed. Elsevier Appl. Sci. London \& New York.

ORTEGA-CALVO, J. J; M. HERNÁNDEZ-MARINÉ y C. SÁIZJIMÉNEZ (|99|): Biodeterioration of building materials by Cyanobacteria and Algae. International biodeterioration, 28 (1/4): 165-185.

ORTEGA-CALVO, J. J; M. HERNÁNDEZ-MARINÉ y C. SÁIZJIMÉNEZ (1992): Experimental strategies for investigating algal deterioration of stone. $7^{\circ}$ Int. Congress on deterioration and consservation of stone, Lisboa, 15-18 jun. 1992. pag: 541-549.

ORTEGA-CALVO, J. J; P. M. SÁNCHEZ-CASTILLO; M. HERNÁNDEZ-MARINÉ Y C. SÁIZ JIMÉNEZ (1993a): Isolation and characterization of epilithic chlorophytes and cyanobacteria from two Spanish cathedrals (Salamanca and Toledo). Nova Hedwigia, 57 (I/2): 239-253.
ORTEGA-CALVO, J. J; M. HERNÁNDEZ-MARINÉ y C. SÁIZJIMÉNEZ (1993b): Niches for Phototrophic Microorganisms in Stone Monuments. In: R. Guerrero \& C. Pedrós-Alió (eds). Trends in Microbial Ecology; pag: 673-676.

ORTEGA-CALVO, J. J.; HERNÁNDEZ-MARINÉ y C. SÁIZ-JIMÉNEZ (1993c). Cyanobacteria and algae on historic buildings and monument. In: K.L. Garg, N. Garg \& K.G. Mukerji (eds). Recent Advances in Biodeterioration \& Biodegradation. I: 173-203.

PARKER, B. C. y H.C. BOLD (196I): Biotic relationships between soil algae and other microorganisms. American Journal of Botany, 48: $185-197$.

PATRICK, R. y C. REIMER (1975): The diatoms of the United States. Monographic series Academy of Natural Sciences of Philadelphia, vol II, part. I. 213 pag.

PIETRINI, A. M. (1989): Fontana del Tritone. Studi ed interventi di carattere biologico. Istituto Centrale del Restauro-ICR. 4 pags.

PIETRINI, A. M. Y S. RICCI (1993): Occurrence of a calcareous blue-green alga, Scytonema julianum (Kütz) Meneghini, on the frescoes of a church carved from the rock in Matera, Italy. Cryptogamic Botany, 3: 290-295.

REALINI, M.; C. SORLINI y M. BASSI (1985): The Certosa of Pavia: I case of biodeterioration. Actes $V^{\circ}$ Congress International sur l'alteration et la conservation de la pierre. Lausanne, pag: 627-632.

RICCI, S.; A.M. PIETRINI \& M. R. GIULIANI ( 1985): Il ruolo delle Microalghe nel degrado biologico degli intonaci. L'intonaco: storia, cultura e tecnologia. Convegno di Bressanone, 24-27.6.1985.

RICCI, S., A.M. PIETRINI \& M. R. GIULIANI (1988). A contribution to the knowledge of the algal flora of archeologic remains: The Foro Romano. Convegno di Frascati 1988.

SÁIZ-JIMÉNEZ, C; J. GARCÍA-ROWE; M.A. GARCIA DEL CURA, J. J. ORTEGA-CALVO, E. ROEKENS y R. VAN GRIEKEN (1990): Endolithic cyanobacteria in Maastricht limestone. The Science of the Total Environment, 94: 209-220.

SÁNCHEZ CASTILLO, P. (1981): Cianofitas de la ciudad de Granada Trab. Dept. Bot. Univ. Granada, 6: 29-48.

SÁNCHEZ CASTILLO, P. (1983): Clorofitas de la ciudad de Granada. Trab. Dept. Bot. Univ. Granada, 8: 63-79.

VIGO, T. L. (1980): Protection of textiles from Biodeterioration. pp: I 8-26. In: F. Pertegato. Conservation and Restoration of Textiles. Ed.CISST. Milano. pp. 285 